\title{
6 The United Kingdom smart meter rollout through an energy justice lens
}

\author{
Kirsten E.H. Jenkins, Benjamin K. Sovacool \\ and Sabine Hielscher
}

\section{Introduction}

The United Kingdom's (UK) Smart Meter Implementation Programme (SMIP) creates the legal framework so that an in-home display unit (IHD) and a smart gas and electricity meter can be installed in every household by the end of 2020 . Intended to reduce household energy consumption, the SMIP is one of the world's most complex smart meter rollouts. It is also proving to be a challenging one as a series of obstacles has characterised and potentially restricted implementation. This chapter first gives background to the most recent smart meter roll-out developments in the UK and second, uses energy justice criteria to explore the emergent challenges under the headings of distributional justice, procedural justice and justice as recognition.

We delve into pertinent technical and non-technical issues arising through the lens of energy justice, - a now commonly used structure first introduced by Schlosberg $(2004,2007)$ and Walker (2009) and used in a policy setting by McCauley et al. (2013). As introduced in full in Chapter 3, this includes a focus on three core tenets, which in this chapter manifest as: (1) an analysis of potential distributional benefits and ills, (2) illustrations of the overlaps between smart meters and other social vulnerabilities including poverty, ill health, social integration or rural marginalisation, which lead to the need to recognise particular sections of society and (3) explorations of the role of procedural engagement during the roll-out.

While the energy justice literature is gaining ever-increasing popularity including in the field of energy 'end-use' - no energy justice research has investigated the development of smart meter technologies to date. This chapter makes an early step towards this goal. The success and necessity of doing so is clear as applying these three concepts to an analysis of the UK SMIP provides opportunities to accurately record, present and expose potential forthcoming injustices, with potential policy implications. Thus, in our conclusions and policy recommendations section we present a series of take-home recommendations for policymakers and advocates. We note from the outset that the material presented here builds directly on Sovacool et al. (2017). 


\section{Smart meters in the United Kingdom: an introduction}

To begin, it is necessary to provide background context. This section of our chapter presents the technologies being deployed in the SMIP before describing the anticipated benefits of the scheme and the rollout timeline.

Smart meters have been implemented in several European countries, with Italy and Sweden being the first to complete their rollout processes. Other countries have prepared or started their rollout over the last $5-10$ years. The UK is among the European Union (EU) countries anticipating a positive business case, with the Department of Business, Energy and Industrial Strategy (BEIS) presenting that case that as of 2016, 'the net present value (NPV) for the domestic rollout of smart meter in GB is now estimated to be £3.8bn' (BEIS, 2016, p. 13).

The goal of the SMIP is to develop and implement technologies that can collect, distribute, and analyse electricity and gas use and production data in order to assist current energy demand and supply management (Pullinger et al., 2014). In this regard, a 'smart meter' in the UK setting has been defined by the Office of Gas and Electricity Markets (Ofgem, 2011) as, 'a gas and electricity meter that is capable of two-way communication'. It measures energy consumption in the same way as a traditional meter but has a communication capability that allows data to be read remotely and displayed on a device within the home or transmitted securely externally. The meter can also receive information

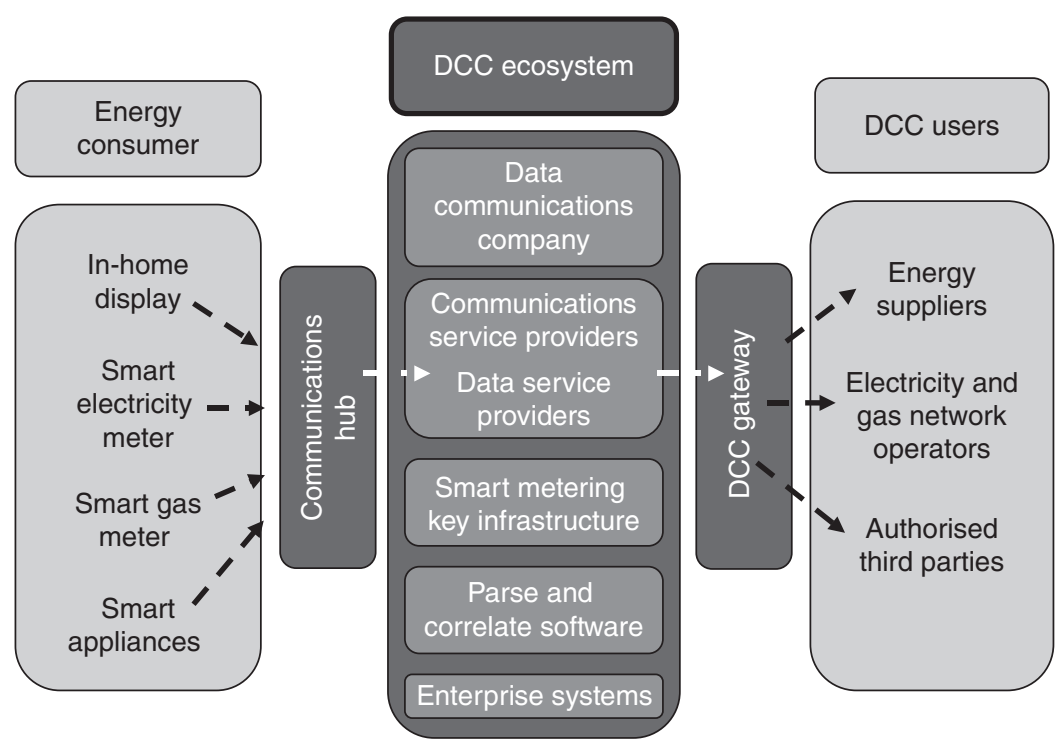

Figure 6.1 Key components of the smart meter communication service and service providers.

Source: the authors. 
remotely, e.g. to update tariff information or switch from credit to prepayment mode. This is, in short, an elaborate way of describing automated meter reading or remote meter diagnostics. One component of the system - the 'in-home display' or IHD - is a monitor that, through a connection to the smart meter, delivers consumers with information about their energy consumption and costs. The UK is peculiar in that it pushes both separate gas and electricity meters and promotes the use of IHDs, which is not the norm. Beyond the provision of these core units, the SMIP also involves the changeover of wireless networks, data and communications companies (DCCs), service users, and electricity and gas suppliers - a configuration of social and technical interactions shown in Figure 6.1.

The government aims to install smart meters - or smart meter ecosystem - in every home in Scotland, Wales and England/(Smart Energy GB) by December 2020 (BEIS, 2016). Whether this is compulsory has remained confusing. Some energy companies have stated that consumers would only be 'offered' smart meter units, whereas others have, as of July 2017, implied that the rollout would be mandatory (Meadows and Brodbeck, 2017).

\section{Proposed benefits}

An advanced metering energy infrastructure enabled by smart meters is said to create the building blocks for a smart grid, including smarter energy management services. This is one of several expected benefits that have been linked to the UK rollout, many of which are sustainability oriented. As a summary, this includes the fact that:

- Energy suppliers are expected to reduce their operational overheads associated with high level of consumer service enquires and manual meter reading and as a result increase customer loyalty. Moreover, they are able to introduce wider range of tariffs and services.

- Network operators are said to benefit through improving the efficiency and responsiveness of the network and enable a greater penetration of renewable technologies into the network.

- Consumers are argued to benefit through empowerment to more appropriately control their energy flows, reducing their bills as they become more aware of their energy consumption. Smart meters are also said to allow easier transferring between energy suppliers and increased billing accuracy (see the summary of benefits in, for instance, McKenna et al., 2012).

Indeed, these are a few of 67 short- and longer-term benefits identified by Sovacool et al. (2017) (and summarised in Table 6.1).

According to the BEIS (previously the Department of Energy and Climate Change (or DECC)) the total costs of the SMIP were estimated to be approximately $£ 8$ to $£ 11$ billion, whereas the financial benefits could be as high as £17.1 billion when factoring in improvements in air quality and the savings anticipated for both consumers and suppliers. 
Table 6.1 Sixty-seven anticipated short-and long-term benefits to smart meters in the UK

No. Short-term benefits

1 Offer an alternative to pre-payment meters or bring down costs of pre-payment meters

2 Help consumers to budget

3 Increase energy efficiency awareness

4 Feedback on energy use

5 Carbon savings

6 Provide real-time information on energy costs

7 Provide information to make informed choices/greater understanding

8 Remote reading, avoid home calls

9 Energy bills accurate

10 Saving energy/reduce consumption

11 Manage their energy use, avoid waste

12 Customers install microgeneration

13 Remote switching credit and prepayment

14 Smoother switching between suppliers

15 Wide range of tariffs and incentive packages from suppliers

16 Suppliers to reduce costs

17 Customers save money/reduce costs

18 Better services from energy companies

19 Energy network planning

20 Drive uptake of renewable electricity

21 Reduce demand for heat

22 Billions in net benefits to the economy

23 Future innovation

24 Jobs

25 Drive a more vibrant and competitive market

26 Offset price rises

27 Access a full range of energy management tools

28 Changing the way we think about energy

29 Help vulnerable customers

30 Pre-payment replaces by smart meter

31 Promote community energy

32 Consumers more active in the energy system

33 Suppliers offer more cost effective tariffs

34 Record how much consumed $1 / 2 \mathrm{~h}$ period

35 Promote distributed generation or distributed energy resources

36 One day switching

Long-term benefits

37 Demand-side management

38 Reduce peak loads via time of day tariffs

39 Network reinforcement and peak generation avoided

40 Advanced management techniques/automated demand-side response

41 Reduced energy consumption

42 Consumers more flexible and responsive to market signals

43 Smart grid

44 Electric vehicle promotion

45 Automated responses to changes in network

46 Enhanced monitoring flow across the network 
Table 6.1 Continued

No. Long-term benefits

47 Deal with intermittence

48 New products and services/innovation

49 Vibrant, competitive market in energy supply and energy management

50 Improved network efficiencies

51 Update microgeneration

52 Turning off non-essential electrical appliances

53 Energy network management

54 Smart Energy Services supported

55 Smart energy market

56 Network operators understand loads on infrastructure

57 Network operators plan investments

58 Network operators respond faster to supply loss

59 Avoid the need to invest in additional network/and generation capacity

60 Generate capacity to meet peak demand

61 Support smart apps and automated appliances

62 Enhance resilience

63 New opportunities for storage

64 Consumers take advantage of lower price periods

65 Peak shaving

66 Develop a domestic smart appliance industry

67 Large industrial consumers and small-scale generators capacity market

Source: Sovacool et al. (2017), with permission.

\section{Rollout programme}

The rollout of the UK's SMIP policy, technical and regulatory apparatus began in 2010 and is composed of several phases: (1) the policy design stage, (2) the foundation stage and (3) the main installation stage. Within the policy design stage (July 2010-March 2011) the technical specifications and implementations model were negotiated. It was decided that energy suppliers should take responsibility for the rollout and installation of smart meters. The Smart Meter Central Delivery Body (SMCDB) was established with the aim to increase awareness about smart meters, alongside the currently operative Smart Energy GB marketing campaign ('the national campaign for the smart meter rollout').

In addition to setting up the implementation programme, a large-scale trial project, Energy Demand Research Project (ERDF) was conducted from 2007 onwards and trials ended in autumn 2010. As argued by Darby (2011, p. 6), 'they took place at a time when policy of smart metering was already developing, so the full findings and lessons have not been available to inform policy development during this period'.

Skipping forward in the timeline, the household installation phase during which most will have their smart meter installed, started at the end of 2016. This start date was pushed back twice from 2014 until November 2016 because of several technical difficulties. This included the technical difficulties of 
enabling broader interoperability so that consumers can switch more easily between suppliers. Currently, energy supplier still install the SMETS 1 (Smart Metering Equipment Technical Specification) smart meter version that go 'dumb' once the householder switches suppliers and the roll out of SMETS 2 devices that enable switching has been repeatedly delayed.

Despite positive potential (Table 6.2), however, capturing these benefits has been elusive, and the implementation of the SMIP has been replete with obstacles. The programme is substantially delayed. Up until September 2017, 8.6 million smart meters have been installed (BEIS, 2017b), corresponding to 15.38 per cent of the target number of 56 million. Now, to make sure that the SMIP meets targets for the remainder of the programme, suppliers must complete installations at a rate of about 40,000 per day. The Institute of Directors stated in 2017 that

The programme has already failed to deliver interoperable meters for switching, is behind schedule, is over-budget and wedded to out of date technology. Not only that, the legal obligation on suppliers to install potentially incompatible meters by the deadline of December 2020 or else pay large fines is already pushing up inflationary costs in wages and advertising.

Alongside the above issues, concerns have also arisen around potential customer resistance to smart meters (see National Audit Office, 2014).

Table 6.2 Estimated benefits to the smart meter implementation programme in the UK

\begin{tabular}{lccc}
\hline & $\begin{array}{l}\text { Domestic } \\
(£ \mathrm{~m})\end{array}$ & $\begin{array}{l}\text { Non-domestic } \\
(£ \mathrm{~m})\end{array}$ & $\begin{array}{l}\text { Total } \\
(\mathrm{Em})\end{array}$ \\
\hline $\begin{array}{l}\text { Consumer benefits (from energy saving and } \\
\text { microgeneration) }\end{array}$ & 4,295 & 1,437 & 5,732 \\
$\begin{array}{l}\text { Supplier benefits (including avoided site visits, } \\
\text { reduced inquiries etc.) }\end{array}$ & 7,970 & 295 & 8,265 \\
$\begin{array}{l}\text { Network benefits (reduced losses, reduced outage } \\
\text { notification calls, fault fixing, avoided investment } \\
\text { from ToU (distribution/transmission) etc.) }\end{array}$ & 877 & 112 & 947 \\
$\begin{array}{l}\text { Generation benefits (avoided investment in } \\
\text { generation from peak shifting through ToU) }\end{array}$ & 803 & 49 & 852 \\
$\begin{array}{l}\text { UK-wide benefits (including CO } \\
\text { air quality) }\end{array}$ & 867 & 440 & 1,307 \\
\begin{tabular}{l} 
Total \\
\hline
\end{tabular} & 14,812 & 2,333 & 17,103 \\
\hline
\end{tabular}

Source: Sovacool et al. (2017), with permission.

Note

$\mathrm{ToU}=$ Time of Use. $\mathrm{UK}=$ United Kingdom. $\mathrm{CO}_{2}=$ Carbon dioxide. 


\section{Conceptualising smart meters through an energy justice lens}

In the following sections we present the results of our restructured analysis according to each tenet of the energy justice framework, distributional justice, justice as recognition and procedural justice (see also Chapter 3 ). We do so in order to demonstrate the social challenges associated with the rollout process, as well as to position a series of policy recommendations that may smooth its execution. We do not provide an in-depth overview of each of these terms as to do so would duplicate material elsewhere in this book. As an abbreviated summary, however, the notion is as follows: distributional justice refers to the unequal distribution of benefits and ills resulting in this case, as a result of an energy project (Jenkins et al., 2017); procedural justice considers access to decision-making processes that govern the distributions outlined previously and manifests as a call for equitable procedures that engage all stakeholders in a non-discriminatory way; whereas justice as recognition expresses concern for the fair engagement of all individuals in conditions where they are free from physical threat and are offered complete and equal political right (Jenkins et al., 2016).

\section{Distributional justice}

Our analysis revealed numerous technical and non-technical distributional challenges resulting from the SMIP. The most frequently discussed relate to the technology and unequal access to it. In the work published by Sovacool et al. (2017), across a systematic review of 47 articles, 60 per cent discussed variations of 'technological', 'technical' or 'engineering' impediments.

As one illustration, the early meters distributed in 2014 would not function properly in one-third of UK homes, including in particular, high-rise flats, basements and remote areas. This leads to unequal access and the marginalisation of particular locations and social groups. Part of the cause of this difficulty was the chose to pursue a less-customary Wi-Fi or Bluetooth mechanism called Zigbee. Within high-rise blocks, where meters tended to be located in basements, the signals failed to make it through thick walls. The result was the need to test more expensive hardwired cables as well as area network radio systems. Lewis and Kerr (2014) draw the conclusion that the SMIP forsake plans to implement the rollout to inaccessible flats and tower blocks, removing approximately 7 million homes from participation.

Technical disbenefits also appeared for people that did have access. Gosden (2015) reports that as of early 2015, one-tenth of the 1.3 million smart meters installed in the UK did not function as 'smart' meters, but as traditional ones requiring manual readings. Moreover, OVO Energy, who supply both gas and electricity, reported that 6 per cent of their customers were unable to view or pay their bills on their installed meters. EDF also reported technical issues with 0.5 per cent of their installations (Palmer 2015a). More recently, Utility Week's (2017, p. 4) market research implies that over one-tenth of households will 
require multiple visits to complete smart meter instillations - a figure that could add around $£ 1$ billion to the total cost of the SMIP programme. In this scenario, limitations with the technology led to the unequal distribution of systems burdens.

Building from the above theme, numerous media outlets reported that large numbers of households were 'trapped' with malfunctioning smart meters, as well as reporting large swings in usage rates displayed on the IHDs, and many consumer complaints (Shannon 2015). These issues were compounded by apparent meter incompatibility where, if a household wanted to change energy suppliers, they had to wait (occasionally over a year) for a new meter. In some instances, smart meters were converted back to 'dumb' types that depended on manual estimates or readings (Meadows and Brodbeck, 2017; Palmer, 2015b). Other consumers complained that their units no long worked even if they were only switching between tariffs even with the same energy company (Brignal, 2016). Concerns have also arisen around the ability of hackers and cyber-terrorists to interfere with systems, where there is some fear that individuals may be able to break in, disrupt grid reliability or intercept bills and personal data, thereby enabling theft or fraud.

Beyond device siting and accessibility, distributional injustices also related to the uneven impacts of the cost of the SMIP programme and its components. Lewis and Kerr (2014) outline that the IHD requirement will cost approximately $£ 800$ million in total, but that there are fears that users fail to engage with the units long term. They also state that the IHD requirement could be removed and replaced by a phone, tablet or personal computer app that could connect to the network with no additional need for hardware installation or cost (although we must acknowledge that these cheaper alternatives may also present distributional challenges as not everyone has ready access to smart phones, tablets or an internet connection (with an impact on the vulnerable groups we later go on to discuss)). Here then, the burdens and benefits of the rollout are distributed unevenly. What is more, even in 2012 there were several devices capable of identifying and displaying consumption data for electric appliances in a similar way and at a much cheaper cost (Thomas, 2012). This includes the OWL meter, an approximately $£ 40$ plug-in device that displays energy use over time, giving consumers 'a clear, accurate picture' of their usage (Thomas, 2012, p. 1061). In this regard, there appeared to be cheaper alternatives that would not present such a high burden to customers through their energy tariffs.

Through their cost-benefit analysis, the National Audit Office (2011) outlined that despite anticipated savings for energy suppliers, the empowerment benefits for consumers were more uncertain, especially as costs will be passed directly to them through higher tariffs and bills. Furthermore, the overall gain for households appears dependant on the extent to which energy suppliers pass savings onto consumers - something that is not guaranteed. The Public Accounts Committee (2012) of the House of Commons noted similar concerns, outlining that (1) most benefits will be distributed to the suppliers and not the 
consumers (who have to pay for the cost of the smart meter), (2) that the benefits of smart meters will only be realised if uptake is widespread and they are used appropriately, both of which are again, not guaranteed and (3) that still, benefits were unlikely to reach vulnerable customers and/or those on prepayment meters. This is an even greater risk when you consider that the $£ 430$ cost for a gas and electricity meter will be related to consumers directly. The fact that most benefits appear to go to producers while the consumers pay the costs for the rollout may be considered one of the biggest distributional inequities. In critical accounts, some academics (e.g. Strengers, 2013 and Balta-Okzan et al., 2014) question the promises associated with smart meters, smart grids, smart homes and demand-side benefits, for instance, arguing that they are promoted by powerful interests. Verbong et al. (2013, p. 121) suggest that: 'Although smart grids are claimed to be in the interest of the end-user, there is some ambiguity about that. (...) Despite all promises, it is not so clear which interests are primarily served by smart grid developments.'

\section{Procedural justice}

Alongside more technical barriers preventing equal access were a series of procedural justice concerns relating to how particular social groups were or were not engaged in decision-making processes about the SMIP rollout (recognising that not everyone can be), and whether the way they would use the system had been considered.

Pullinger et al. (2014, p. 1158) give the opinion that the SMETS standards (the technical standards behind the SMIP) have been developed in a top-down, industry-led way 'with little input from, or attention to the householder'. This lack of consumer engagement implies disconnect between the technical operationalisation of the SMIP and the narrative of consumer benefit being at the heart of it. This may be one reason for what appears to be growing resistance to the programme (typified by disengagement with the smart meter, or never becoming a smart meter user, for example). Chilvers and Longhurst (2016, p. 596) note, in this regard, that during one of the SMIP trials (the Visible Energy Trial) individuals 'resisted' the smart meter by intentionally failing to use it appropriately. This delayed the collection of data and results and ultimately, convinced others not to engage in the trial. They go on to suggest at least two potential reasons for this resistance: (1) that the IHD was perceived as giving only incremental, inconsequential reconfigurations of consumption and behaviour change that did not meaningfully save energy and (2) users felt that their meters placed unfair burden on them to take responsibility for carbon reductions over industry and government groups, for example. Here, there are clear breaches in what is deemed to be necessary procedural justice.

Compounding concerns over manifestations of consumer resistance, BaltaOzkan et al.'s (2014) comparison of smart meter perceptions in Europe illustrated resistance frames in terms of accountability and responsibility. Their UK-wide focus groups revealed the expectation that the government was 
responsible for addressing climate change, not individuals. IHD and smart meter users also opposed because of control and privacy concerns - the belief that they represented an extension of power companies, which were taking over their private lives and homes. Indeed, this manifested as recurring concern for the potential of smart meters to 'compromise security' and 'invade privacy' (BaltaOzkan et al., 2014, p. 1185).

Yet more consumers expressed frustration caused by the technical problems by intentionally overriding the system or practicing inefficient behaviour. One implication is that users may opt out of the SMIP. A second is that those coerced into participating could disconnect their IHD, sabotage their meter or could be unwilling or reluctant to share their data with apparently 'devious' companies. In short, all reasons culminate in mounting resistance where Rose and Thed (2014) report reservations from one supplier that 'up to 20 per cent of customers will refuse to have smart meters installed' and two firms have documented additional costs from dealing with 'reluctant customers'. A recent Smart Energy GB report outlines that 16 per cent of the UK adult population are 'indifferent' to smart meters, with a further 18 per cent in the category of 'rejector' (Smart Energy GB, 2017). Furthermore, smart meters can even increase consumption - an early (2004) EDF trial showed that gas consumption rose by 'almost 50\%' as users became aware of significant under-heating (Mott MacDonald, 2007).

Furthermore, although an August 2017 'Customer Experience study' from BEIS involving 2,015 households found mostly positive reactions to smart meters, it did note that 7 per cent of customers reported being very dissatisfied or somewhat dissatisfied with their smart meter; that 73 per cent of customers were not given any information on data storage and privacy, or how data would be shared; and that 18 per cent of customers indicated they did not even look at the information given on their IHDs (BEIS, 2017a).

In the event observations reported on by Sovacool et al. (2017), which took place between 2015 and 2016, there was also very little focus on what consumers wanted. The only exception was a national grid representative who questioned 'can they manage to deliver what customers and consumers want at the end of the day?' (October 2015). This neglect reinforced the idea that the SMIP is about increasing the provision of information in order to change behaviour (one-way influence), as opposed to creating an energy system that encourages user participation and more 'active' consumerism where participants influence the future of the energy system. This could explain the lack of interest or appearance of resistance.

Where terms such as 'protection', 'engagement', 'consumer benefit', 'enabling' and 'empowerment' appeared in the events observed by Sovacool et al. (2017) there was no real reference to what occurs after consumers were enabled or empowered. Very few considered acceptance, trust and experience. Indeed, in the last event the team observed in November 2016, (the lack of) 'consumer acceptance' was outlined as one of the three key challenges remaining for the rollout. Smart Energy GB were quoted as saying: 
There is no mandate on the part of the consumer although there is mandate on the part of the energy supplier. And that is a real challenge I think for a consumer engagement campaign; how do we make sure every consumer is empowered to say 'yes'.

It is a somewhat bleak representation to suggest that resistance always or frequently occurs, of course. A 2017 commercial survey of more than 1,000 UK consumers advised that 64 per cent with installed meters 'enjoyed better visibility of their energy costs'; 36 per cent reported achieving savings and 76 per cent were impressed by the expertise of the people completing their installation (Utility Week, 2017, pp. 2-3). Nevertheless, improved procedures may be necessary for engaging consumers in both smart meter implementation and use.

\section{Justice as recognition}

It is reasonable to acknowledge that particular groups will encounter problems with any new innovation that required technological or behavioural change, but without careful implementation, the SMIP programme raises the potential exacerbation of pre-existing vulnerabilities among some consumer classes - an issue of justice as recognition or the unequal burdens (or benefits) presented to particular groups. Notably, early evidence shows that the SMIP may unduly burden the elderly, ill, less educated, those living in social housing and/or those in the rural periphery at the expense of a preference for supplier and companyoriented cost savings and economic competition. If the SMIP can lessen the expenditure needed for meter readings, network operation, grid reinforcement and electricity generation, among other areas, then consumers should benefit from lower energy practice whether or not they make behavioural changed. In reality, however, many forms of social inequity and injustice emerge.

A synthesis report compiled by DECC (2015a, 2015b) presented the results of a 4,016 consumer survey, 169 in-depth household interviews with users on both credit and prepayment meters, 12 focus groups, and consumption data for over 10,000 households and revealed, ultimately, that consumers from so-called 'vulnerable groups' 'are likely to need more help if they are to obtain the full benefits of smart metering' (DECC, 2015a, p. 22). The report outlined in particular that

Older smart meter customers, those from lower social grades, those with the lowest total annual household incomes (below $£ 16,000$ ), those with no formal qualification and those who lived with someone who had a longterm health condition or disability were less likely to say the IHD was easy to use or to say they knew how to operate its different functions.

(DECC, 2015a, pp. 22-23)

Barnicoat and Danson (2015) ran an experimental project for elderly tenants in rural Scotland where they used sensors and IHDs to measure and display 
household energy costs over a period of seven months. The aim was to investigate how households interacted with IHDs, or what they term 'smart energy monitors'. The elderly were soon a particularly relevant sample group given that they were often in their homes for large amounts of time, are high users of domestic energy, may receive fixed incomes that necessitate fuel rationing, require higher temperatures due to old age and may also suffer physical limitations that affect their interactions with technological equipment. Barnicoat and Danson's research revealed that despite greater price feedback, little 'awareness' occurred. Specifically, households did not understand the link between IHDs and electrical appliance use. Further, the study suggested that the primary benefit of the IHDs was not perceived as being for households, but for the energy supply company engineers as it gave them information about household use. This was at odds with expectations. Citizens Advice (2017) rehearsed similar concerns in a report critiquing the SMIP for its potentially negative impacts on low-income and elderly households, including in particular, those without a formal education, who did not speak English fluently, or who suffered from a long-term illness. According to their report, some consumers were distressed, confused about, or unable to use smart meter information.

On the grounds of the events the authors observed, Sovacool et al. (2017) discuss a mix of responsibilities necessary to make sure vulnerable groups are accounted for and benefit from, smart meters. Smart Energy GB discussed 'shared responsibility with suppliers around behaviour change' (Smart Energy GB, 2016) but did not go on to outline how this responsibility was shared. The idea of 'partnering up' between different organisations to support vulnerable users was also discussed with the aim of 'mobilising' energy champions, volunteers, and a community fund in order to support people so they could 'make use of the benefits'. Again, however, Sovacool et al. reported that there was little discussion of who would guide these activities or what role they would play in the SMIP rollout. This may be the cause of DECC's (2015b) move to ask Smart Energy GB to advance stronger advisory and supporting materials, including increasing its role as a facilitator of knowledge exchange and enabling locallevel networks and partnerships.

Alongside elderly populations, which are the most frequently discussed in connection to the SMIP, there are several less frequently documented increased vulnerabilities. Echoing Sovacool et al. (2017), we briefly discuss two: (1) increased rural peripheralisation and (2) externalities and lifecycle impacts. The SMIP may worsen the urban/rural divide, or unwittingly increase the preference for smart meter instillation in urban areas but not rural, countryside homes. For example, access to the dedicated network connection services required for a functioning smart meter system varies widely across the UK, with notably lower accessibility outside of urban centres (Ofcom, 2016). The housing stock is also more challenging to access, meaning that installation often requires more travel mileage and person hours. This leads to an inequitable, albeit understandable, focus on 'easy to manage' areas with well-established delivery and logistic networks and larger installation volumes. 


\section{Conclusions and policy recommendations}

As an outcome of our energy justice evaluation, the main contribution of this chapter is to inform current policies and practices concerning the SMIP and national energy policy attempts to decarbonise electricity and heat in the UK. Most especially, we highlight insufficient consumer engagement with both the rollout and the physical infrastructure of smart meters and IHDs and failure to fully engage with potential burdens and benefits for vulnerable households. We position this finding in the light of critiques coming from a diverse set of actors such as academics, consumer bodies, parliamentary committees and newspaper articles.

We suggest that it is necessary to better account for, and manage, potential vulnerabilities as well as produce a broader range of outreach and communication materials that are easier to understand, especially among the elderly or the poor (Citizens Advice, 2017). While we acknowledge that Smart Energy GB have created a marketing partnership programme to reach out to vulnerable customers and increasingly emphasise community engagement (Smart Energy GB, 2018), this process must focus not only on outreach and communication, but also on the depth of engagement and alternative models for it, such as community-led rollout promotions. We encourage the creation of meaningful feedback mechanisms to engage consumers, which requires, in part (more) time to trial different mechanisms in diverse settings. Doing so can help overcome social barriers, perhaps increasing smart meter implementation and ultimately, long-term affectivity. Otherwise, the route to a smarter energy system will be littered with social obstacles.

Finally, for several expected benefits to be realised, consumers need to play an active part with regards to how and when they consume (and sometimes produce) energy (Buchanan et al., 2016). Particularly in the UK, ambitious consumer-oriented aims have been set out in the SMIP (Pullinger et al., 2014). Smart meters are argued to 'putting consumers in control, ending estimated bills and helping people save energy and money' (BEIS, 2017b, p. 1). In addition to rolling out smart meters, the UK government has decided to provide every home with 'real-time' feedback with their energy use through an IHD in order to facilitate the expected benefits. The inclusion of IHD has been highly debated. Energy suppliers have argued that cheaper digital options would be more applicable, as they would reduce the cost of the overall rollout whereas academics have argued over the effectiveness of feedback devices to help people manage their energy consumption (such as Darby, 2006). In 2010, Darby (2010, p. 449) argued that 'it is risky for utilities and their regulators to adapt a 'fit and forget' attitude to any new technology in the belief that it will, unsupported, achieve their goals and be acceptable to consumers'.

While we have used the UK as a case study, our material contributes to debates beyond this one case study. Some $€ 51$ billion will be spent on smart meter initiatives in the near future across the EU (Darby, 2010). In 2013, only about 10 per cent of households in the EU had a smart meter, but the 
European Commission has mandated that this number rise dramatically to 80 per cent by 2020 (Viitanen et al., 2015). The European Commission (2017) reports that Member States have committed to rolling out close to 200 million smart meters for electricity and 45 million for gas by 2020 at a total potential investment of $€ 45$ billion. This study elucidates some of the technical and social elements befuddling attempts to rapidly diffuse smart meters across homes and cities - findings that have relevance for those wishing to better understand the temporality and complexity of both national and household energy transitions.

\section{References}

Balta-Ozkan, N., Amerighi, O. and Boteler, O. (2014) A comparison of consumer perceptions towards smart homes in the UK, Germany and Italy: Reflections for policy and future research. Technology Analysis and Strategic Management 26(10): 1176-1195.

Barnicoat, G. and Danson, M. (2015) The ageing population and smart metering: A field study of householders' attitudes and behaviours towards energy use in Scotland. Energy Research and Social Science 9: 107-115.

Brignal, M. (2016) Smart meters: an energy-saving revolution or just plain dumb? Guardian. 1 October 2016. Available at: www.theguardian.com/money/2016/oct/01/ smart-meter-energy-saving-revolution-cut-bills-gas-electricity.

BEIS (2016) Smart Meter Roll-out Cost-benefit Analysis. HM Government, London, UK. Available at: www.gov.uk/government/publications/smart-meter-roll-out-gb-costbenefit-analysis.

BEIS (2017a) Smart Meter Customer Experience Study: Post-Installation Survey Report. August 2017. Available at: www.gov.uk/government/uploads/system/uploads/attachment _data/file/641076/Post-install_key_findings_report_FINAL_24082017_PUBLICA TION.pdf.

BEIS (2017b) Smart Meters Implementation Programme 2017 Progress Update. HM Government, London, UK. Available at: https://assets.publishing.service.gov.uk/government/uploads/system/uploads/attachment_data/file/671930/Smart_Meters_2017_ update.pdf.

Buchanan, K., Banks, N., Preston, I. and Russo, R. (2016) The British public's perception of the UK smart metering initative. Threats and opportunities. Energy Policy 91: $87-97$.

Chilvers, J. and Longhurst, N. (2016) Participation in transition(s): Reconceiving public engagements in energy transitions as co-produced, emergent and diverse. Journal of Environmental Policy and Planning 18(5): 585-607.

Citizens Advice (2017) Smart support: Support for vulnerable consumers in the smart meter roll-out. 9 March 2017. Available at: www.citizensadvice.org.uk/Global/ CitizensAdvice/Energy/Smart\%20Support.pdf.

Darby, S. (2006) The effectiveness of feedback one energy consumption - A review for DEFRA of the literature on metering, billing and direct displays. Environmental Change Institute. Oxford University, UK.

Darby, S. (2010) Smart metering: what potential for householder engagement? Building Research and Information 38(5): 442-457.

DECC (2015a) Smart Metering Implementation Programme: DECC's Policy Conclusions - Early Learning Project and Small-scale Behaviour Trials. Department 
of Energy and Climate Change, London, UK. Available at: www.gov.uk/government/ publications/smart-metering-early-learning-project-and-small-scale-behaviour-trials.

DECC (2015b) Smart Metering Early Learning Project: Synthesis Report. Department of Energy and Climate Change, London, UK. Available at: www.gov.uk/government/ publications/smart-metering-early-learning-project-and-small-scale-behaviour-trials.

European Commission (2017) Smart Metering Deployment in the European Union Joint Research Centre. Available at: http://ses.jrc.ec.europa.eu/smart-metering-deploymenteuropean-union.

Gosden, E. (2015) Energy smart meter roll-out may be 'costly failure', MPs warn. Telegraph, 5 March 2015. Available at: www.telegraph.co.uk/news/earth/energy/11456193/ Energy-smart-meter-roll-out-may-be-costly-failure-MPs-warn.html.

IoD (2017) Future Proofing Energy. Available at: www.iod.com/Portals/0/PDFs/Campaigns $\% 20$ and\%20Reports/Infrastructure/Future-proofing-Energy.pdf?ver=2017-06-01$183745-103$.

Jenkins, K., McCauley, D., Heffron, R., Stephan, H. and Rehner, R. (2016) Energy justice: A conceptual review. Energy Research and Social Science 11: 174-182.

Jenkins, K., McCauley, D. and Warren, C.R. (2017) Attributing responsibility for energy justice: A case study of the Hinkley Point Nuclear Complex. Energy Policy 108: 836-843.

Lewis, D. and Kerr, J. (2014) Not Too Clever: Will Smart Meters be the Next Government IT Disaster? Institute of Directors, UK. Available at: www.emraware.com/ Documents/smart_meters_not_too_clever.pdf.

Meadows, S. and Brodbeck, S. (2017) Smart meter roll-out: Is getting one still compulsory? Telegraph, 8 July 2017. Available at: www.telegraph.co.uk/bills-and-utilities/gaselectric/smart-meter-roll-out-getting-one-still-compulsory/.

McCauley, D., Heffron, R., Stephan, H. and Jenkins, K. (2013) Advancing energy justice: The triumvirate of tenets. International Energy Law Review 32(3): 107-110.

McKenna, E., Richardson, I. and Thomson, M. (2011) Smart meter data: Balancing consumer privacy concerns with legitimate applications, Energy Policy 41: 807-814.

Mott MacDonald (2007) Appraisal of Costs and Benefits of Smart Meter Roll Out Options. Final Report. Mott MacDonald, Brighton, UK.

National Audit Office (2011) Preparations for the Roll-out of Smart Meters, HC 1091, Session 2010-2012, 30 June 2011, London. Available at: www.nao.org.uk/idoc. ashx?docId=6854152F-711C-4B5A-AB79-C829BA80A504\&version=-1.

National Audit Office (2014) Update on Preparations for Smart Metering. Available at: www.nao.org.uk/report/update-on-preparations-for-smart-metering/.

Ofcom (2016) Communications Market Report: Scotland. 4 August 2016. Available at: www.ofcom.org.uk/_data/assets/pdf_file/0024/43476/CMR_Scotland_2016.pdf.

Ofgem (2011) Factsheet 101. Smart metering - What it means for Britain's homes. 31 March 2011. Available at: www.ofgem.gov.uk/sites/default/files/docs/2011/03/ consumersmartmeteringfs_0.pdf.

Palmer, K. (2015a) Billing glitches for first customers of $£ 11$ bn smart meter roll-out. Telegraph, 23 May 2015. Available at: www.telegraph.co.uk/finance/personalfinance/ energy-bills/11622798/Billing-glitches-for-first-customers-of-11bn-smart-meter-rollout.html.

Palmer, K. (2015b) 1.5 million smart meters won't work when you switch energy supplier. Telegraph, 7 June 2015. Available at: www.telegraph.co.uk/finance/personalfinance/ energy-bills/11643750/1.5-million-smart-meters-wont-work-when-you-switch-energysupplier.html. 
Public Accounts Committee (2012) Preparation for the Roll-out of Smart Meters, Sixtythird Report of Session 2010-2012, HC637, The Stationery Office, London, UK. 17 January 2012. Available at: www.publications.parliament.uk/pa/cm201012/cmselect/ cmpubacc/1617/1617.pdf.

Pullinger, M., Lovell, H. and Webb, J. (2014) Influencing household energy practices: A critical review of the UK smart metering standards and commercial feedback devices. Technology Analysis and Strategic Management 26(10): 1144-1162.

Rose, D. and Thed, M. (2014) Unveiled: New £200 'smart' meters every household must pay for (but may not work), The Mail on Sunday, 7 July 2014. Available at: www. thisismoney.co.uk/money/bills/article-2681954/Unveiled-New-200-smart-metershousehold-pay-not-work.html.

Schlosberg, D. (2004) Reconceiving environmental justice: Global movements and political theories. Environmental Politics 13(3): 517-540.

Schlosberg, D. (2007) Defining Environmental Justice: Theories, Movements and Nature. Oxford University Press, Oxford, UK.

Shannon, L. (2015) Just how smart are these energy meters? Financial Mail on Sunday, 17 May 2015. Available at: www.thisismoney.co.uk/money/bills/article-3084432/ERRORSmart-energy-meters-leave-hundreds-thousands-households-billing-limbo.html.

Smart Energy GB (2016) Citizens Advice Partners with Smart Energy GB to Spread the Word about Smart Meters. 18 July 2016. Available at: www.smartenergygb.org/en/ resources/press-centre/press-releases-folder/citizens-advice-partnership.

Smart Energy GB (2017) Smart Energy GB Consumer Engagement Plan and Budget 2018. 15 December 2017. Smart Energy GB, London, UK. Available at: www. smartenergygb.org/en/about-us/essential-documents.

Smart Energy GB (2018) Annual Report and Accounts: Year Ended 31st December 2017. Available at: www.smartenergygb.org/en/about-us/essential-documents.

Sovacool, B.K., Kivimaa, P., Hielscher, S. and Jenkins, K. (2017) Vulnerability and resistance in the United Kingdom's smart meter transition. Energy Policy 109: 767-781.

Strengers, Y. (2013) Smart Energy Technologies in Everyday Life. Palgrave Macmillan, Basingstoke, UK.

Thomas, S. (2012) Not too smart an innovation: UK plans to switch consumers to smart gas and electricity meters. Energy and Environment 23(6-7): 1057-1074.

Utility Week (2017) Smart metering: Challenging times lead to strange bedfellows, 10 May 2017. Available at: http://utilityweek.co.uk/news/smart-metering-challengingtimes-lead-to-strange-bedfellows/1302322\#.WU_6OWjyvIV.

Verbong, G.P.J., Beemsterboer, S. and Sengers, F. (2013) Smart grids or smart users? Involving users in developing a low carbon electricity economy. Energy Policy 52: 117-125.

Viitanen, J., Connell, P. and Tommis, M. (2015) Creating smart neighborhoods: Insights from two low-carbon communities in Sheffield and Leeds, United Kingdom. Journal of Urban Technology 22(2): 19-41.

Walker, G. (2009) Globalizing environmental justice, Global Social Policy 9(3): 355-382. 